\title{
25 años de tornados en Cataluña (1992-2017)
}

https://doi.org/10.31978/639-19-010-0.563

\author{
Joan Arús Dumenjón ${ }^{\text {(jarusd@aemet.es) }}$
}

${ }^{1}$ AEMET / Delegación Territorial en Cataluña

\begin{abstract}
RESUMEN
Desde 1992 tenemos registrados en Cataluña unos 400 fenómenos tornádicos, incluyendo tornados, mangas marinas y reventones o fenómenos similares como turbonadas, frentes de racha, derechos y casos dudosos. Las tubas no se han tenido en cuenta, pero si las considerásemos tendríamos unos 600 casos con un aumento significativo en los últimos años. Para una climatología 25 años es poco, ya que sería necesario un mínimo de 30 años o más (35-40) tratándose de fenómenos raros como es el caso de los tornados. No obstante, con estos 25 años se presenta una primera aproximación de climatología tornádica por comarcas. Previamente se describen los principales y más mediáticos fenómenos anteriores a 1992, los EF2 y EF3 del periodo en estudio así como los métodos y fuentes de recogida de datos y tasación, además de los entornos meteorológicos más favorables.
\end{abstract}

PALABRAS CLAVE: tornado; manga marina; reventón; turbonada; derecho; tuba.

\section{INTRODUCCIÓN}

Esta presentación un tanto nostálgica tiene su motivación principal en la asistencia del autor por primera vez a un simposio nacional de predicción, que fue a finales de 1992, cuando se desarrolló el III Simposio y el autor recién destinado en Barcelona asistió en calidad de oyente. A pesar de que las mangas marinas son y han sido un fenómeno relativamente frecuente en la costa catalana, como veremos más adelante, me impactaron las conferencias que presentaron Miquel Gayà (GAYÀ y Soliño, 1996) y Antonio Soliño (Soliño y GAYÀ, 1996), sobre Caps de Fibló en Baleares, palabra que escuché por primera vez, y que es la forma habitual de designar a las mangas y tornados en Baleares. Poco después, en 1994 a raíz del tornado de l'Espluga de Francolí, tuve ocasión de conocer y colaborar con Miquel Gayà en el trabajo de campo de este episodio, una colaboración que ha continuado hasta nuestros días. En el IV Simposio de 1996 (Arús et al., 1999), ya me estreno presentando un trabajo sobre la situación del 31 de agosto de 1994 que dio lugar a uno de los tornados más mediáticos ya que su vídeo dio la vuelta al mundo siendo de los primeros en España filmados; lo cual dio lugar a otro estudio de cálculo de la velocidad a partir de las imágenes fotogramétricas a cargo de Miquel Gayà y Ángel Redaño (GAYÀ y REDAÑo, 1999). En el V Simposio de 2002 presento otro trabajo relacionado, un estudio de reventones cálidos (ARús, 2002) y, tras esta pausa de 15 años, y como no podía ser de otra manera, presento este trabajo resumen de todos los fenómenos tornádicos vividos y registrados, incluyendo mangas, tornados y reventones.

A pesar de que las trombas son y han sido un fenómeno conocido y habitual en la costa catalana, la tromba famosa por excelencia es la de Sant Feliu de Guíxols-Calonge-Palamós del 2 de septiembre de 1965 (SÁNCHEZ-LAUlhÉ et al., 2017) y (ARús, 2018); quizás por las dimensiones y por la cercanía a la costa de Sant Feliu de Guíxols así como la duración, unos 35 minutos, unos 2 km longitud, y que fuera domingo, etc. Lo cierto es que dio tiempo a los curiosos a buscar la cámara fotográfica para inmortalizarla: más de 80 fotos, algunas en color y todo, así como un vídeo de 2 minutos ha podido recoger el activista cultural y fotógrafo 


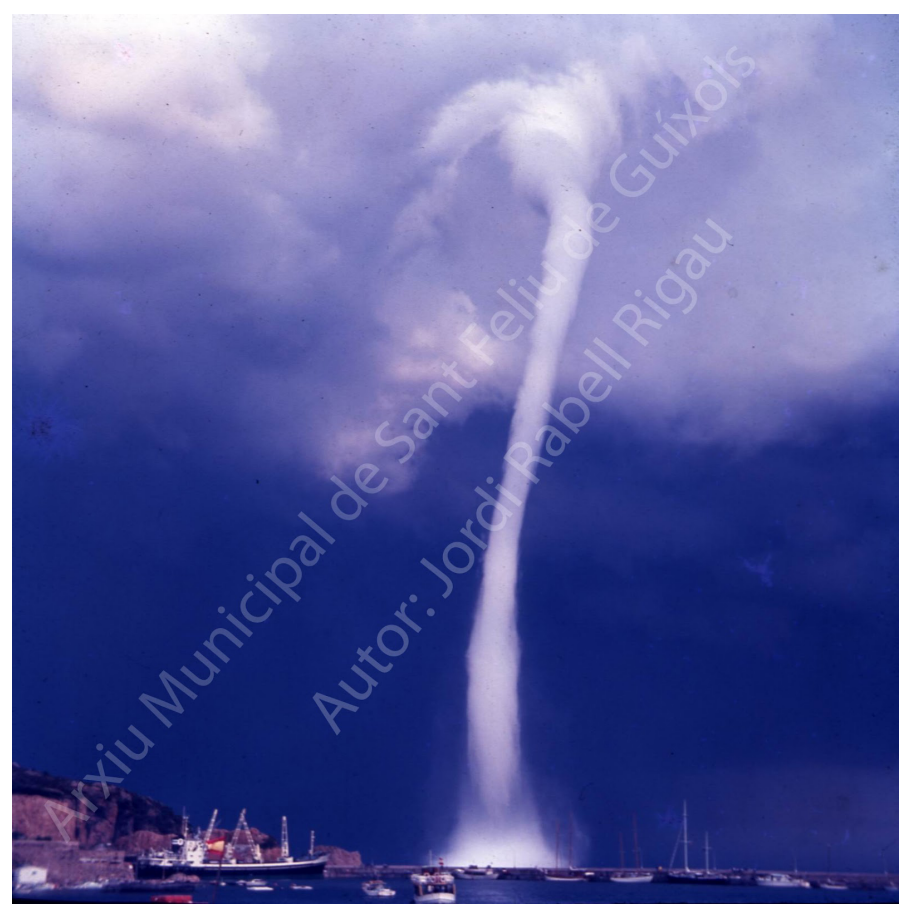

\section{Figura 1.}

La tromba famosa por excelencia es la de Sant

Feliu de Guíxols-Calonge-Palamós del 2 de

septiembre de 1965.

Jordi Rabell, fotógrafo guixolense.

http://arxiumunicipalguixols.blogspot.com.es/

2012/02/la-tromba-marina-de-1965-en-color.html

guixolense Jordi Ferrando para la conmemoración del 50 aniversario de la tromba ${ }^{1}$, como se puede ver en la figura 1. Representa un punto de inflexión en los estudios de tornados en Cataluña ya que se considera la primera manga marina fotografiada que además adquirió difusión internacional ya que un turista holandés que la fotografió le dedicó una comunicación en la revista científica Hemel en Dampkring (BloKLAND, 1965). Su silueta sirvió para ilustrar al capítulo «torbellinos marinos» del libro Las Tormentas de Editorial Planeta. (CAStelló, 2009).

No obstante, los registros de fenómenos tornádicos antiguos constituyen una base de datos poco homogénea y completamente abierta a nuevas incorporaciones, la última esta referencia aportada por la cuenta de twitter del archivo municipal de Sant $\mathrm{Pol}^{2}$ conmemorando los 120 años de una manga marina.

En (GAYÀ, 2015) podemos encontrar una amplia descripción de todos los casos conocidos en la costa catalana agrupados así: antes de 1800, 1801-1900, 1901-1980 y 1980-2012; mostrando una distribución bastante regular. En (GAYÀ et al., 2011) se agrupan así: 1950-1979 y 1980-2009; y en este caso se nota un desplazamiento del máximo de casos observados hacia la costa central claramente influenciado por la densidad de población, como se puede ver en la figura 2.

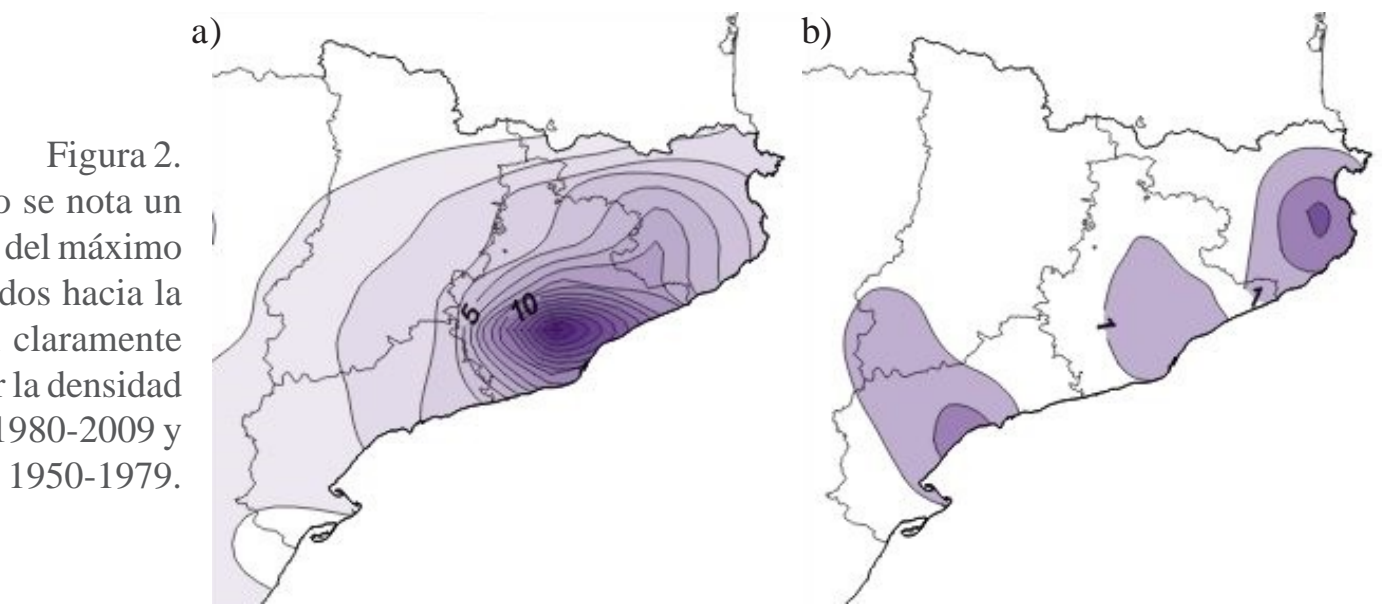

\footnotetext{
1 http://latrombade165.blogspot.com.es/.

2 https://mobile.twitter.com/ArxiuSantpol/status/1023470709035737088?s=03.
} 


\section{BASE DE DATOS, CONSIDERACIONES Y ALGUNOS CASOS}

A partir de 1992 — coincidiendo con mi incorporación al GPV de Barcelona—, pero especialmente a partir de 1994 — coincidiendo con el tornado de l'Espluga de Francolí—, voy anotando todos los fenómenos tornádicos de los que tengo conocimiento a la vez que voy incorporando todos los antiguos de los que se tienen noticias, fundamentalmente por libros y prensa antigua. Como se ha dicho, el primer trabajo de campo —que fue de 3 días por encargo del INM — se desarrolló en l'Espluga de Francolí en septiembre de 1994, con métodos muy rudimentarios, unos planos que nos facilitaba el Ayuntamiento, lápiz y brújula; siguiendo la metodología propuesta por Gayà (GAYÀ, 2015). El siguiente trabajo de campo se desarrolla en Batet de la Serra en 1996, también con Miquel Gayà desplazado por encargo de INM y por primera vez estrenamos un GPS. En el trabajo de campo del tornado de Castellcir de 18 de octubre de 2006 — también con Miquel Gayà y en colaboración con el Servei Meteoròlogic de Catalunya — se realiza una parte del reconocimiento en helicóptero aunque los resultados no son todo lo buenos que se podría esperar. En el trabajo de campo del tornado del 21 de marzo de 2006 de Ivars d'Urgell, el último que me encargó AEMET, por primera vez utilizamos la tecnología móvil Android con ploteo de wayponts online y Google Earth, como se puede ver en la figura 3. En uno de los últimos trabajos de campo realizados, el del 7 de enero de 2018, probablemente el de mayor recorrido de los que se tiene conocimiento en esta base de datos con 45,5 km (RodríGuez et al., 2018) se utiliza por primera vez un dron. Ha sido uno de los trabajos de campo más extensos y con días más cortos, ya que es el segundo en un mes de enero de la serie y el primer trabajo de campo en estos días de pocas horas de luz. Se realizó el mismo día 7 por la tarde y continuó días después siguiendo la metodología propuesta en RoDRíGUEZ et al., 2018. El estudio permitió certificar que se había producido un tornado de intensidad EF2 según la escala de Fujita mejorada (WIND SCIENCE AND ENGINEERING CENTER, 2006) y enlazar la traza de daños con los destrozos ocasionados por el tornado del otro lado del Pirineo (Plouvien, 2018).

Como se puede apreciar la base de datos con visitas y trabajos de campo sería muy pequeña, por lo que a mí se refiere. No obstante, recopilando todas las visitas de otros compañeros y multitud de gente como meteorólogos aficionados y colaboradores de AEMET además de la información ofrecida por medios de comunicación, pero en especial por el equipo de meteorólogos de TV3, hemos podido ampliar la base de datos. A partir de 2003 y 2004 la fotografía digital, las webcams e Internet aportan multitud de casos. Posteriormente

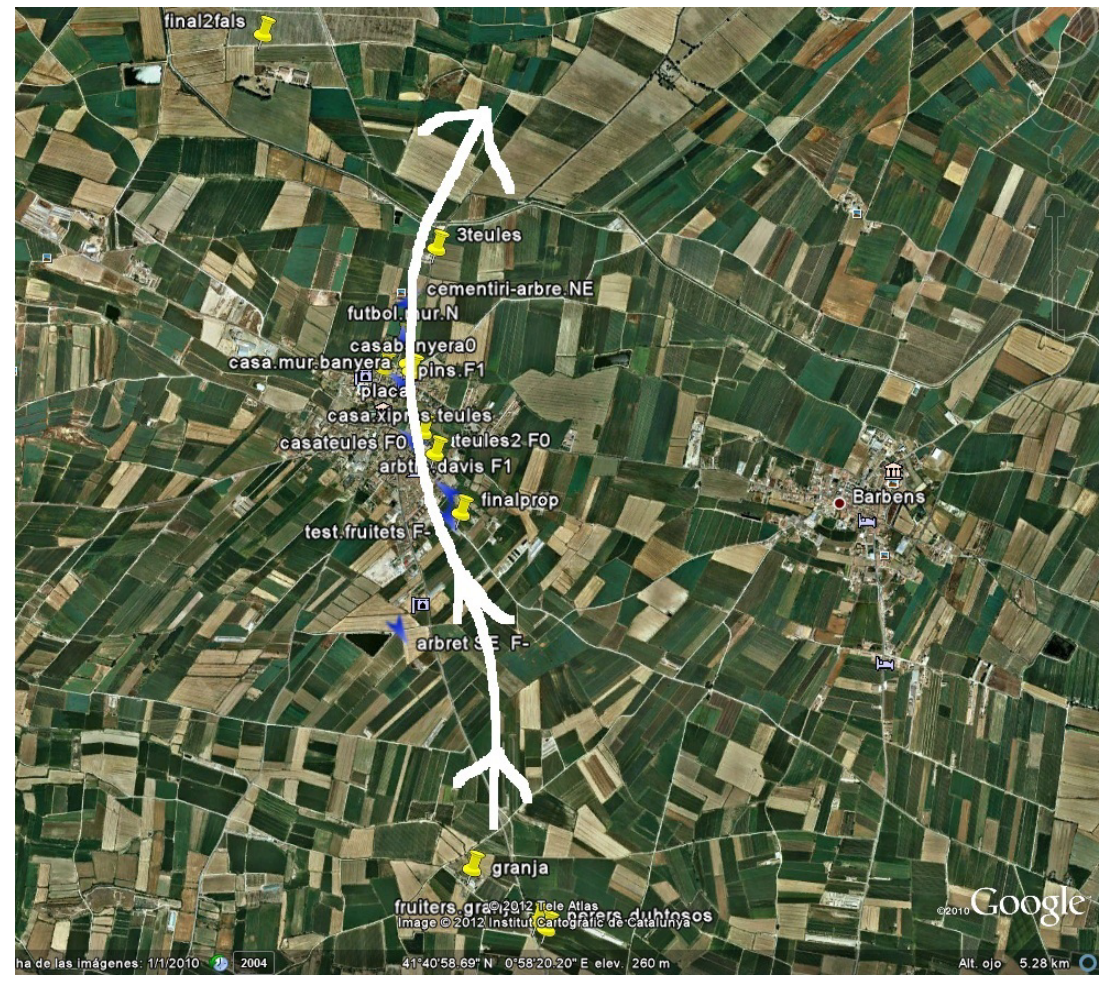

Figura 3.

En el trabajo de campo del tornado del 21 de marzo de 2006 de Ivars d'Urgell, por primera vez utilizamos la tecnología móvil Android con ploteo de Wayponts online y Google Earth. 
las redes sociales y los smartphones favorecen la difusión inmediata de los fenómenos tornádicos, en especial Twitter; mi cuenta de Twitter @ jarusgpv data de 2010, en su origen para este menester. Casi a la par los modelos numéricos en línea como Estofex ayudan a que los cazatornados puedan estar en el lugar y momento adecuado, incluso de noche, dando lugar a muchas fotografías nocturnas con largas exposiciones donde aparecen mangas marinas entre rayos. Así las cosas, es fácil suponer que la percepción de estos fenómenos ha aumentado considerablemente en estos últimos años y, lejos de estancarse, la eclosión de la telefonía móvil y la mensajería instantánea como WhatsApp y Telegram hacen que continúe aumentando la percepción, con las limitaciones que puede tener, como por ejemplo la aparición de fakes que hay que saber filtrar adecuadamente. Por ejemplo, en el tornado de Valls del 18 de octubre de 2017, sin ninguna fotografía conocida, voluntaria o involuntariamente circuló por redes sociales rápidamente una fotografía del tornado de Vilabella del 30 de mayo de 2014.

En un primer momento también se anotaban tubas, unas 600, pero el rápido crecimiento de estas observaciones así como las pocas o nulas referencias anteriores hacen poco útil la comparativa. De entre todos los fenómenos registrados o conocidos, 490 exactamente entre el 1 de septiembre de 1992 y el 1 de septiembre de 2018, 133 son tornados, 280 mangas y 77 reventones (o similares como derechos, turbonadas, frentes de racha, reventones no convectivos, etc., o casos dudosos). De todos ellos, unos 50 tienen visita de campo, es decir aproximadamente el $25 \%$ de los fenómenos tornádicos terrestres. No siempre se han podido realizar el mismo día o días siguientes con lo que la zona a explorar queda restringida a bosque ya que las zonas urbanas quedan limpias rápidamente. En la mayor parte de trabajos de campo se ha observado que la dirección de caída de los árboles obedece a un patrón compatible con el desplazamiento de un vórtice (BECH et al., 2009), (GAYÀ, 2005) o (SoliÑo, 2015). También se han tenido en cuenta la relación de árboles afectados o la proporción entre anchura y longitud de la traza (RodRíguez et al., 2018). De todos estos trabajos de campo, destacamos los 10 casos tasados como EF2 que, además casi todos han motivado alguna publicación: l'Espluga de Francolí, 31 de agosto de 1994 (RAmis et al., 1997); Lladurs, 21 de octubre de 2002³; Brucardes-Manresa y Els Hostalets de Balenyà-Centelles, 17 de agosto de 2003 (ARús, 2003) y (LóPEZ y ARús, 2004); El Prat de Llobregat-Aeroport-Sant Boi, 7 de septiembre de 2005 (BECH et al., 2007); Sant Boi-Sant Feliu de Llobregat, 13 de setiembre de 2006 (Mateo et al., 2009); Castellcir, 18 de octubre de 2006 (Aran et al., 2009); Sarral-Miralcamp-Cabra del Camp, 2 de noviembre de 2008 (BECH et al., 2011); Cardona y Cistella-Terrades-Navata-Darnius-Agullana, 7 de enero de 2018 (BECH et al., 2018); incluso el de Cabra del Camp gracias a las imágenes de satélite (ortofotos disponibles en línea, ya sea vía $\mathrm{ICC}^{4} \mathrm{o}$ Google Earth) seguramente será reclasificado como EF3 y, quizás, con el más reciente de 7 de enero de 2018 si, como parece, se confirma la unión de trayectorias con el tornado francés de Maureilles ${ }^{5}$ y a la espera de las ortofotos en línea que suelen tardar en estar disponibles.

Como se ha dicho este corpus de fenómenos tornádicos ha sido posible gracias a observadores y aficionados, peritos del Consorcio de Seguros, medios de comunicación, redes sociales, pero también otras bases de datos como SINOBAS, ESWD, Meteocat, y en especial dos bases de datos particulares con las que se ha fusionado y contrastado: la de Miquel Gayà (1981-2012) y la de Oriol Rodríguez (2000-2018).

\section{ALGUNOS RESULTADOS}

A partir de 1992 y considerando todos los 490 fenómenos se obtiene el gráfico de la figura 4 resultando una media de 4-5 tornados por año y 12-16 mangas marinas, estas en claro aumento, si bien creemos que en gran parte es debido a la mayor percepción y conocimiento. Únicamente en el primer año no se observó ninguna, como se puede ver en la citada figura.

\footnotetext{
3 A pesar de ser uno de los 10 tornados más fuertes es el único que no ha motivado estudio alguno, si bien TV3 emitió un espacio del Tiempo en directo desde Lladurs al dia siguiente, que me sirvió de guía para el trabajo de campo de días después. TN Migdia — 22/10/2002.

4 https://betaportal.icgc.cat/comparador-gificador/.

5 http://www.keraunos.org/actualites/faits-marquants/2018/tornade-maureillas-las-illas-7-janvier-2018-pyrenees-orientales-occitanie.
} 


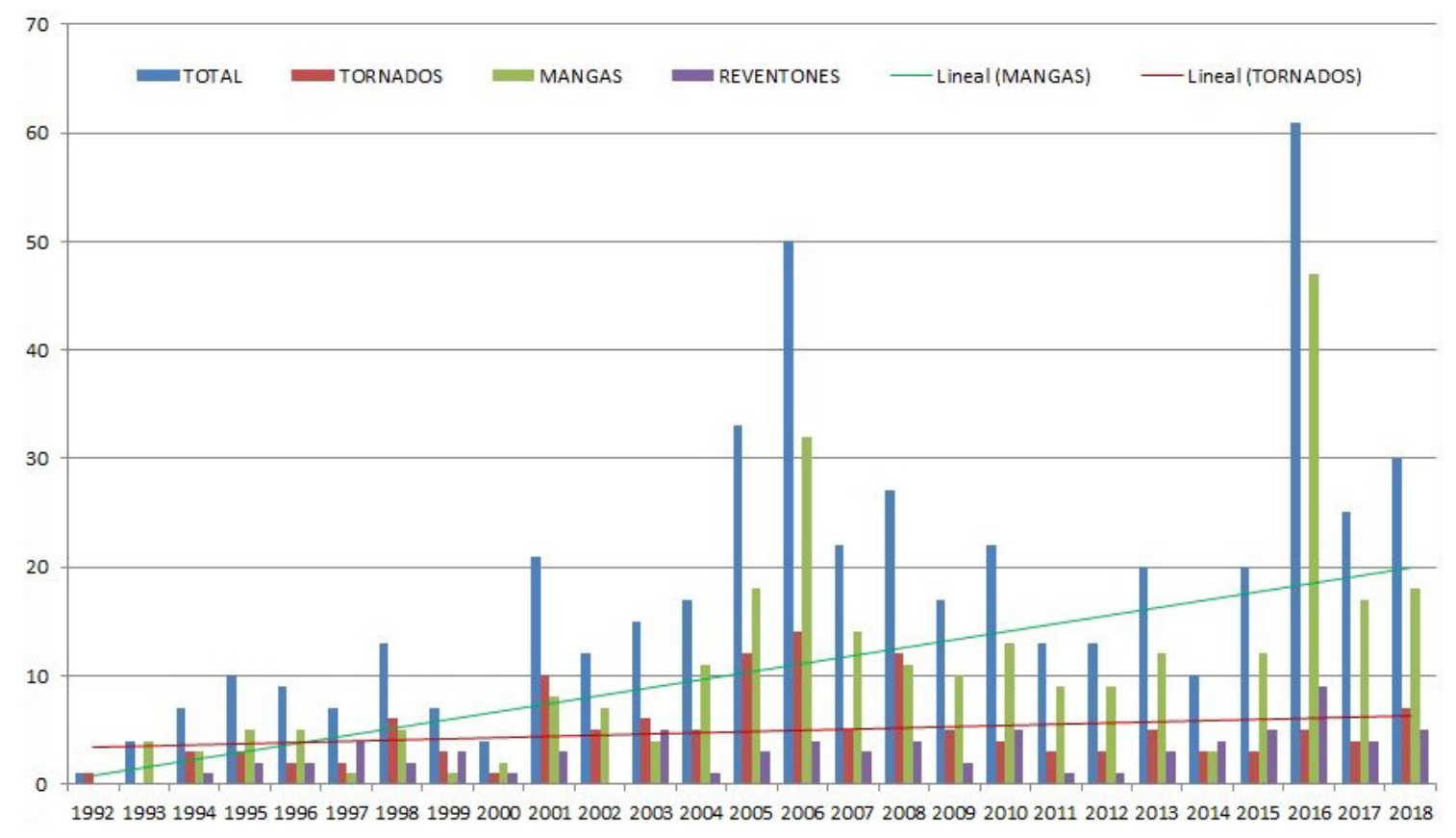

Figura 4. Total de fenómenos tornádicos registrados:

490 exactamente entre el 1 de septiembre de 1992 y el 1 de septiembre de 2018.

a)

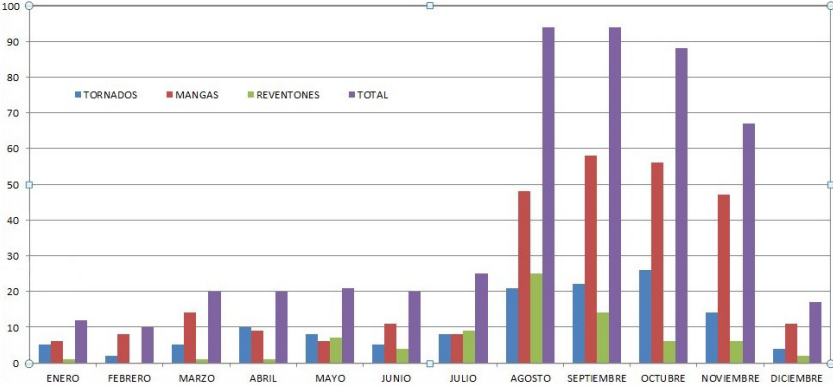

b)

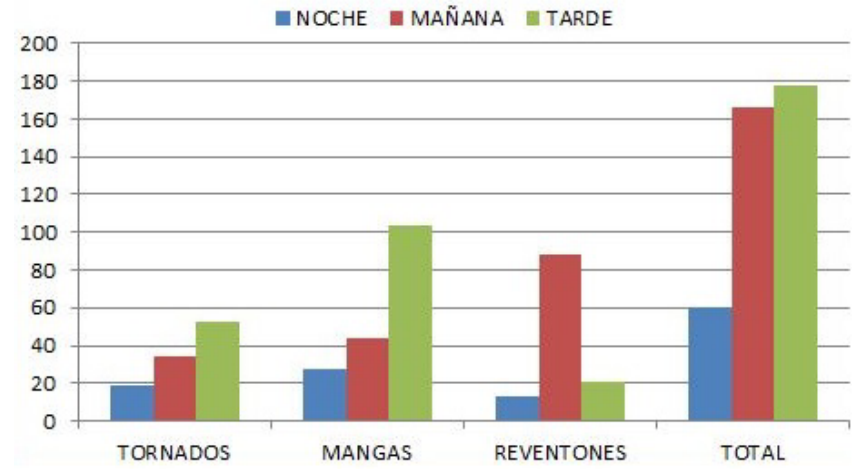

c)

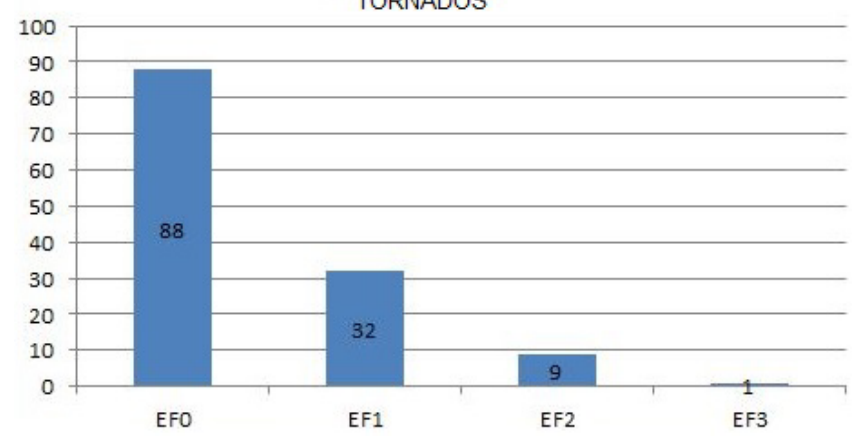

Figura 5. Distribución por: a) meses, b) franjas horarias y c) intensidad EF.
Por meses, como era de esperar, el otoño y finales de verano concentran la mayor parte de fenómenos, como se puede ver en la figura 5a, pero es significativo que todos los meses tienen fenómenos e incluso el mes de enero que solo recogía un caso hasta 2018, en que se ha dado la situación del 7 de enero con 3 tornados y uno de ellos probablemente el más largo de los registrados hasta el momento (BECH et al., 2018) y (RodRíGuez et al., 2018). Por franjas horarias, y al no disponer de las horas exactas de cada uno de los fenómenos, se han agrupado en mañana, tarde y noche, como se puede ver en la figura $5 \mathrm{~b}$. En cuanto a la intensidad, tampoco se tienen todos los fenómenos tornádicos clasificados, resultando el gráfico de la figura $5 \mathrm{c}$.

Por otra se han representado tal como se anotan siguiendo una distribución municipal/comarcal por simplicidad, según las 42 comarcas catalanas, como ya se presentó en una primera publicación (Morales et al., 2009). No obstante, y sobre todo debido el reciente aumento de mangas marinas al límite de las 20 millas, coincidiendo con el límite de la cobertura móvil y flujo de embarcaciones, ya sea de recreo o pesca profesional, hacen necesario el replanteamiento de esta representación gráfica para futuros trabajos. Como ya se observó en Morales et al., 2009 se muestra una distribución comarcal de tornados y 

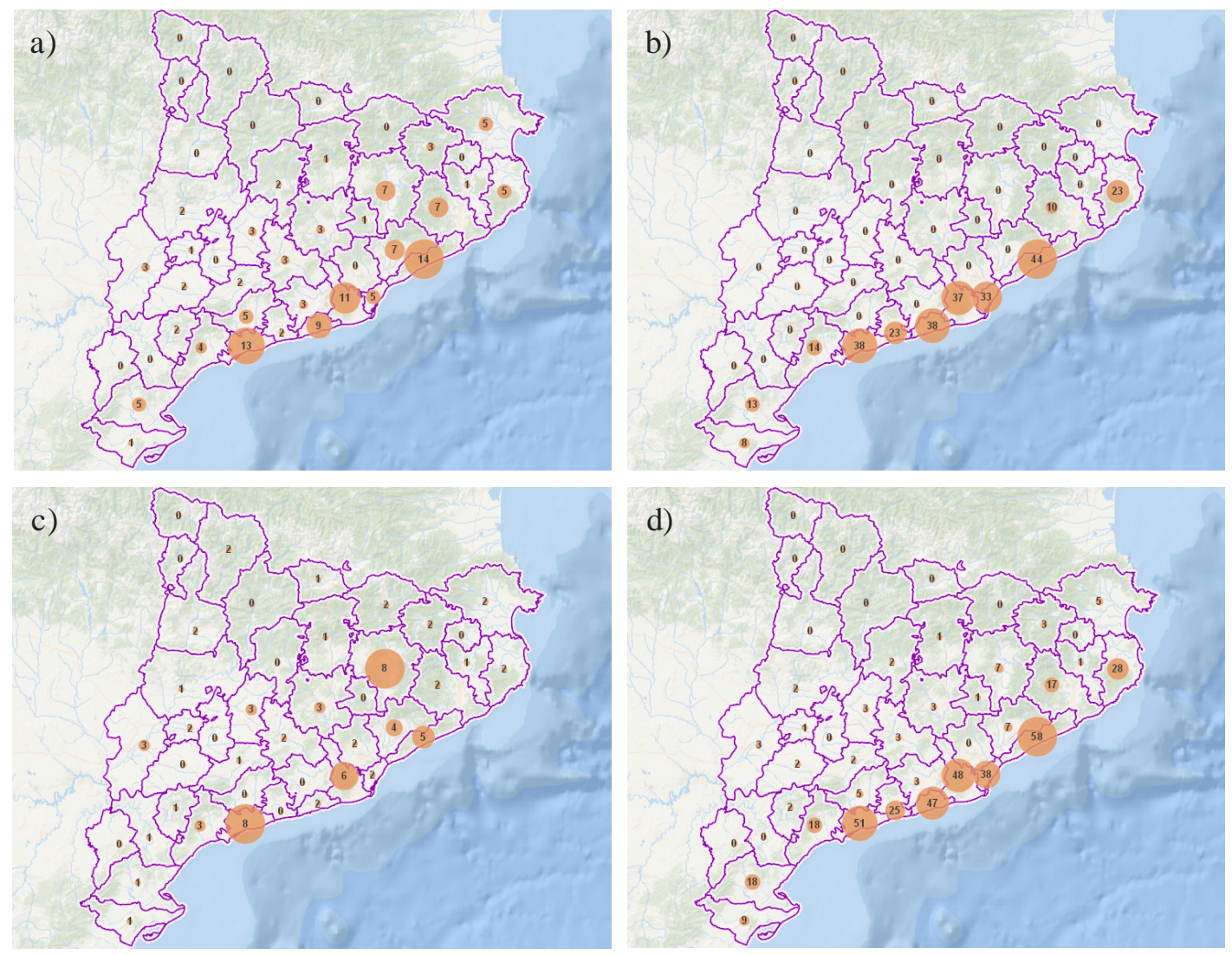

Figura 6. Distribución por comarcas: a) tornados, b) mangas marinas, c) reventones y d) tornados+mangas (vistas desde la costa correspondiente).

mangas marinas con un máximo en la zona del Maresme-Baix Empordà, muy probablemente relacionado con la conocida zona de convergencias de la Tramuntana (zona de convergencia catalano-balear (JANSÀ, 1997) o (PASCUAL y CALLADO, 2002)). Quizás relacionado con la persistente Tramuntana y el mar frío, no se ha observado ninguna manga en la comarca del Alt Empordà a diferencia del extremo sur de la costa, donde a pesar del también fuerte pero quizás no tan persistente viento de Mestral, además de una temperatura del agua de mar mucho más elevada. En la actualización 1992-2018, como se puede ver en la figura 6abcd, se confirma este máximo del sur de la Costa Brava-Maresme así como otros máximos casi del mismo orden en la costa central y en la Costa Daurada y que probablemente son una contribución doble: la zona de convergencias central y sobre todo la de la Costa Daurada (PINEDA et al., 2011), como se puede ver en la figura 7; por otra parte este máximo de la Costa Daurada se correspondería con un máximo relativo de densidad de descargas eléctricas constatado por las redes de descargas, tanto de AEMET (RIESCO et al., 2015) como de Meteocat (PINEDA et al., 2011), como se puede ver en la figura 8 .

Figura 7.

Zonas de convergencia clásicas en la costa catalana (PINEDA et al., 2011).

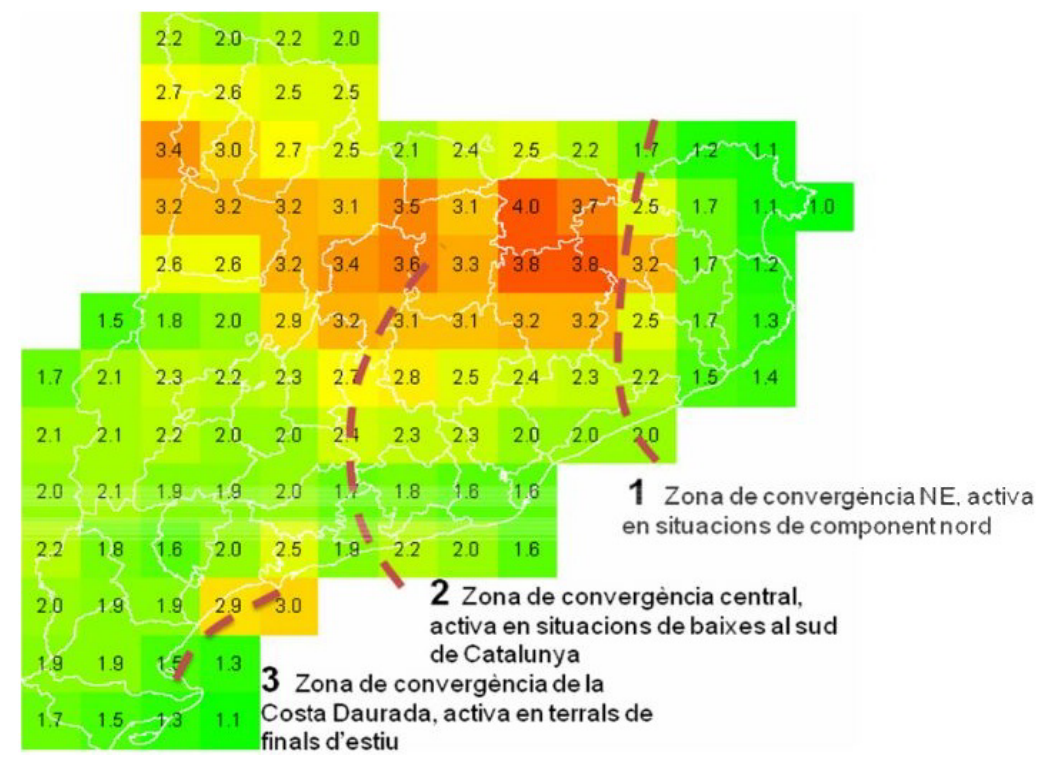



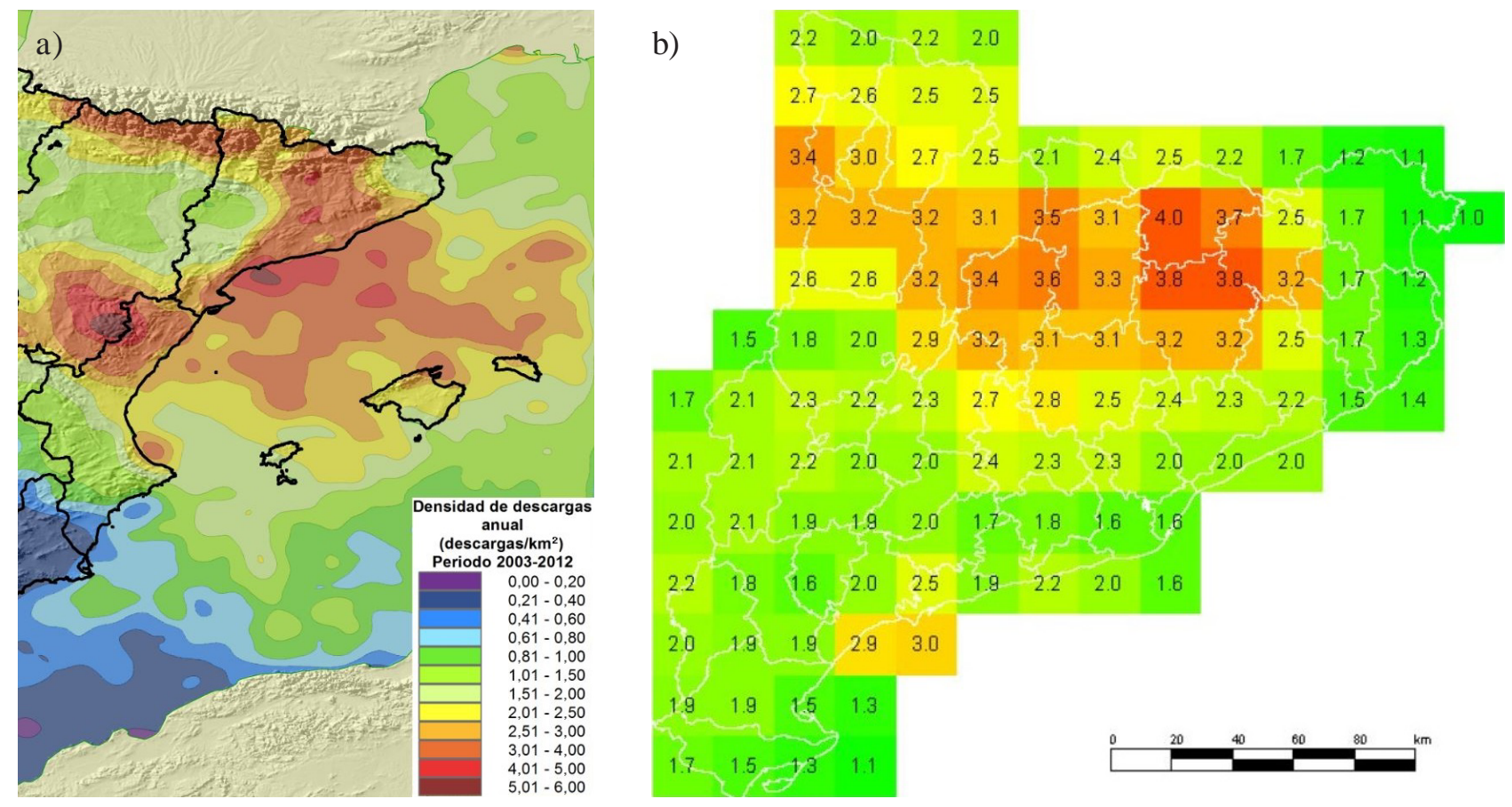

Figura 8. Actividad eléctrica según a) AEMET-Sinobas: densidad anual de descargas eléctricas (número de descargas $/ \mathrm{km}^{2}, 2003-2012$ ); y b) Meteocat: densidad de rayos (rayos $\mathrm{NT} \mathrm{km}^{-2} \mathrm{año}^{-1}$ ) en una cuadrícula de $20 \times 20 \mathrm{~km}$, media del periodo $2004-2008$.

\section{ENTORNOS FAVORABLES}

Una vez mostrado que el fenómeno de las mangas marinas o tornados en la zona no es inusual entramos en el marco sinóptico favorable para ellos. De muchas de las narraciones históricas, por ejemplo en el caso múltiple de marzo de 1883 con 15 mangas (CASTELló, 2009) o (GAYÀ, 2015) ya se describe una fuerte irrupción fría en mar relativamente cálido como detonante de las tormentas que generaron las trombas, como también la de 1962 (ARÚs, 2017) y (SÁNCHEZ-LAULHÉ et al., 2017). Otros se corresponden con forzamiento sinóptico marcado, pasos de vaguadas con o sin frente frío asociados, como sería el caso del último episodio multitornádico del 7 de enero de 2018 (BECH et al., 2018), el caso del derecho del 17 de agosto de 2003 (LóPEZ, 2007), el 7 de septiembre de 2005 en el aeropuerto de El Prat (BECH et al., 2007) o el de Sarral-Miralcamp-Cabra del Camp 2 de noviembre de 2008 (Весн et al., 2011). Otros con poco forzamiento sinóptico aunque sí mesoescálico como el del 21 de marzo de 2006 de Ivars d’Urgell (BECH et al., 2012) y sobre todo efecto diurno como los casos del 31 de agosto de 1994 (RAmis et al., 1999), el 18 de octubre de 2017 en Valls (BECH et al., 2016), el de Castellcir del 18 de octubre de 2006 (ArAN et al., 2009) o el de Vilabella del 30 de mayo de 2014 (BECH et al., 2015). En algunos de los casos se han podido identificar estructuras radar «indiciariamente» supercelulares, por ejemplo en el derecho del 17 de agosto de 2003, el del 7 de septiembre de 2005 en el aeropuerto de El Prat, el de Castellcir del 18 de octubre de 2006, el de Sarral-Cabra del Camp del 2 de noviembre de 2008 o los recientes del 7 de enero de 2018 entre otros y sin que esto quiera decir que los tornados fueran supercelulares. En los primeros estudios no se disponía de la tecnología radar actual, pero aun así en el primer tornado estudiado de l'Espluga de Francolí se concluye que no fue supercelular; a pesar de que en la etapa de madurez de la célula es posible que se observara supercélula (SP) a partir de la imagen TIROS (ARÚs et al., 1999). Comparando con el mapa de presuntas supercélulas que elabora «La Meteorología Extrema» en el foro https://foro.tiempo.com ${ }^{6}$ ya se puede observar que son casi complementarios con lo que la mayoría de fenómenos tornádicos no se corresponderían con SP. Además el máximo de fenómenos tornádicos se da en la costa catalana central si bien de los 10 con EF mayor o igual

\footnotetext{
6 https://foro.tiempo.com/casos-de-presuntas-supercelulas-en-espana-en-2017-normas-y-listado-pagina-1-t148201.252.html.
} 
a 2 solamente 2 se dan en esta zona, y en el caso del aeropuerto de El Prat del 7 de septiembre de 2005 con estructuras radar supercelulares además de fotografías con aspecto rotacional del cumulonimbo tornádico, como se puede ver en la figura 9. En muchos otros casos de los fenómenos tornádicos de la costa catalana se han observado fotos parecidas e incluso recientemente con la eclosión de fotografía digital videos time lapse con aspectos rotacionales claros ${ }^{7}$, lo que haría pensar, cuando menos, en algún tipo de estructuras supercelulares como mini-SP (BECH et al., 2018).

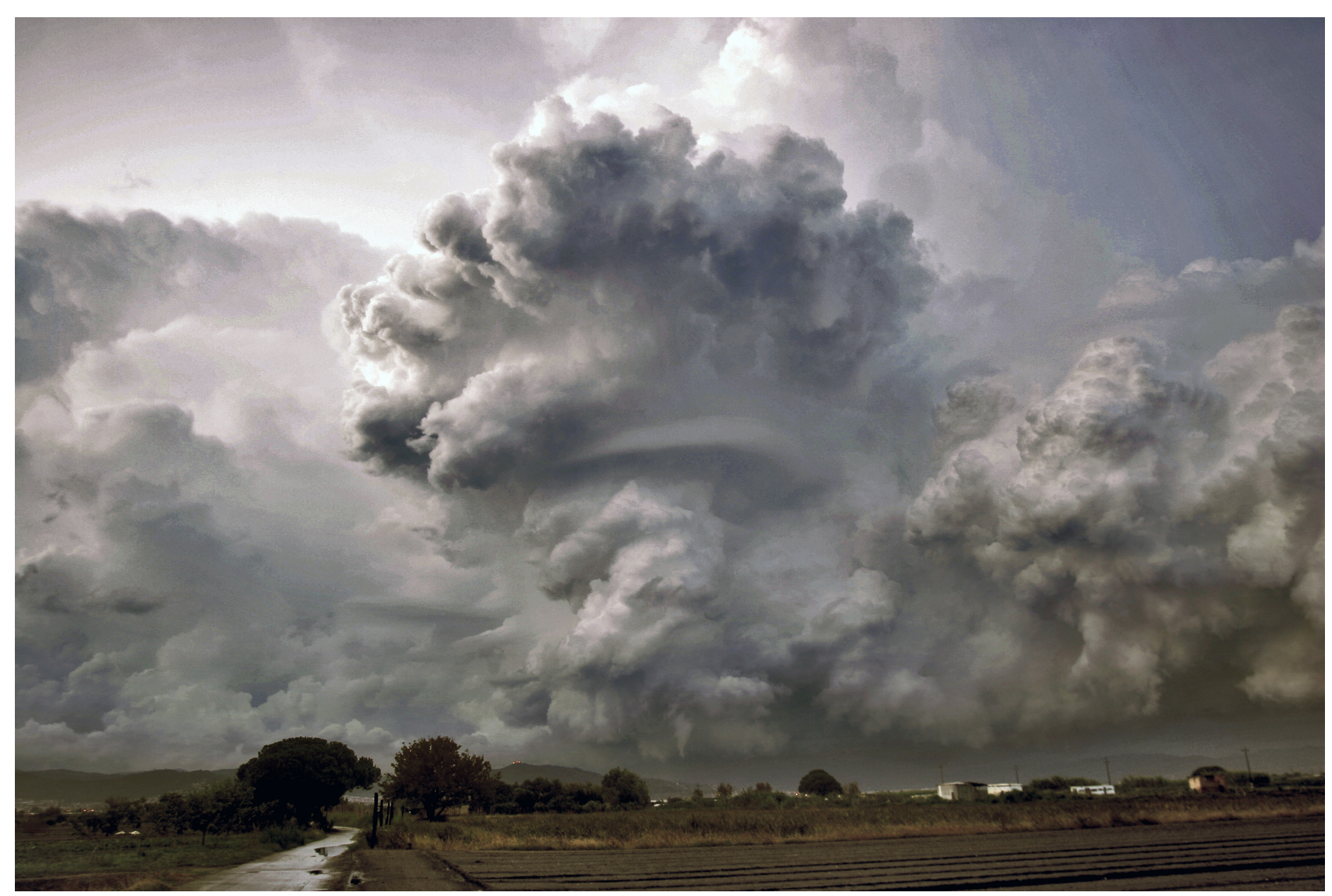

Figura 9. Supercúmulo tornádico. @Manuel Conde.

Además y como podemos ver en los radiosondeos estudiados en los trabajos citados el perfil vertical no presenta valores extremos en los índices que se suelen usar para evaluar la flotabilidad de la columna de aire, salvo quizás el CAPE, pero con valores poco restrictivos y de acuerdo con (RodRíGUEZ, 2014) no se dan tornados EF2 o superiores con valores menores de $500 \mathrm{~J} \mathrm{~kg}^{-1}$. La característica común a todos los casos presentados es el perfil vertical de viento, aun sin ser acusado, presenta una helicidad modesta (efecto sacacorchos) como también se ha demostrado en la mayoría de fenómenos tornádicos de Cataluña (RodRíGUEZ, 2016) que además expone unos umbrales mínimos para los tornados o mangas EF iguales o superiores a EF1. Los resultados indican que la helicidad relativa a la tormenta para la capa 0-3 km, con un valor umbral de $150 \mathrm{~m}^{2} \mathrm{~s}^{-2}$, cizalladura del viento para la misma capa, con un umbral de $15 \mathrm{~m} \mathrm{~s}^{-1}$, y parámetros compuestos como SCP (Supercell Composite Parameter) con un umbral de 1,2 y el índice tornádico universal UTI con un umbral de 0,3 son útiles para distinguir entre tormentas sin tornado y EF1 o eventos tornádicos más fuertes. En este sentido (Perea, 2018) propone usar la helicidad efectiva (Thompson, 2006) entendiendo por capa efectiva el estrato representativo del flujo horizontal que podría alimentar la corriente ascendente en la célula convectiva. SRHe (helicidad relativa a la tormenta en la capa efectiva) discrimina mejor que SRH1km y SRH3km entre supercélulas que dan origen a tornados significativos (EF2 o superiores) y las que no dan lugar a tornados. El concepto de «capa efectiva» se puede extender al cálculo de la cizalladura.

«Formació de mesociclons a la costa Barcelonina?»: http://youtu.be/QZbaM9IjG3I. 


\section{CONCLUSIONES}

Para una climatología 25 años es poco, ya que sería necesario un mínimo de 30 años o más (35-40) tratándose de fenómenos raros como es el caso de los tornados. No obstante, con estos 25 años se presenta una primera aproximación de climatología tornádica por comarcas, que como también se ha comentado no es la mejor representación.

Para el periodo estudiado que va del 1 de septiembre de 1992 al 1 de septiembre de 2018 se obtiene una media de 4-5 tornados año y 12-16 mangas marinas, estas en claro aumento, si bien creemos que en gran parte es debido a la mayor percepción y conocimiento. Es decir aumento sí, pero no. La máxima frecuencia de mangas y tornados se da en la costa central si bien 8 de los 10 tornados más fuertes se han registrado en el interior. Los máximos del litoral probablemente relacionados con zonas de convergencias clásicas así como una temperatura del agua del mar elevada, sobre todo en otoño, como se observa en el máximo relativo de densidad de rayos. A pesar de observarse características supercelulares en las imágenes radar de algunos de los casos estudiados más recientes, no todos lo son, y la mayoría pertenecen al grupo de tornados no supercelulares.

\section{REFERENCIAS}

Aran, M., Amaro, J., Arús, J., Bech, J., Figuerola, F., Gayà, M. y Vilaclara, E., 2009. Synoptic and mesoscale diagnosis of a tornado event in Castellcir, Catalonia, on 18th October 2006. Atmospheric Research, 93, 147-160.

Arús, J., López Pérez, J. M., Ramis, C. y Mestres, A., 1999. Estudio meteorológico del día 31 de agosto de 1994: tornado de l'Espluga de Francolí. 4. ${ }^{\circ}$ Simposio Nacional de Predicción del INM. Instituto Nacional de Meteorología. Madrid. http://hdl.handle.net/20.500.11765/4204.

Arús, J., 2001. Reventones de tipo cálido en Cataluña. V Simposio Nacional de Predicción [CD-ROM]. Instituto Nacional de Meteorología. Madrid. http://hdl.handle.net/20.500.11765/4699.

Arús, J., 2003. Mànegues, esclafits i caps de fibló. Revista de la ACOM, Penell, núm. 16 (noviembre de 2003). https://www.researchgate.net/publication/318530630.

Arús, J., 2017. El fibló del 2 de setembre de 1965 a Sant Feliu. Revista de la ACOM, Penell, núm. 48. https://www.researchgate.net/publication/322129392.

Bech, J., Rodríguez, O., Altube, P., Rigo, T., Pineda, N., Castán, S., Arús, J. y Montanyà, J. 2018. Doppler radar observations of two tornadic thunderstorm cases in the Western Mediterranean Region. 10th European Conference on Radar in Meteorology and Hydrology (ERAD 2018): 1-6 July 2018, Ede-Wageningen, The Netherlands, p. 111. http://library.wur.nl/WebQuery/wurpubs/539463. http://staticm.meteo.cat/wordpressweb/wp-content/uploads/2017/09/29132849/ERAD18-2cases0702.pdf.

Bech, J., Arús, J., Castán, S., Pineda, N., Rigo, T., Montanya, J. y van der Velde, O., 2015. A study of the 21 March 2015 tornadic quasi linear convective system in Catalonia. Atmospheric Research, 158-159, 192-209.

Bech, J., Castán, S., Arús, J., Pascual, R., Cuevas, G., Reigó, T., Pineda, N., Montaña, J. y Van Der Velde, O., 2015. Analysis of the 30 May 2014 tornadic storm in Vilabella, Catalonia. European Conference on Severe Storms 2015, 14-18 September 2015, Wiener Neustadt, Austria. https://meetingorganizer.copernicus.org/ECSS2015/ ECSS2015-87-1.pdf. 
Bech, J., Pascual, R., Rigo, T., Pineda, N., LóPez, J. M., Arús, J. y Gayà, M., 2007. An observational study of the 7 September 2005 Barcelona tornado outbreak. Natural Hazards and Earth System Science, 7, 129-139.

Bech, J., Pineda, N., Rigo, T., Aran, M., Amaro, J., Gayà, M., Arús, J., Montanyà, J. y van der Velde, O., 2011. A Mediterranean nocturnal heavy rainfall and tornadic event. Part I: Overview, damage survey and radar analysis. Atmospheric Research, 100, 621-637.

Bech, J., Gayà, M., Aran, M., Figuerola, F., Amaro, J. y Arús, J., 2009. Tornado damage analysis of a forest area using site survey observations, radar data and a simple analytical vortex model. Atmos. Res., 93, 118-130. https://doi.org/10.1016/j.atmosres.2008.10.016.

Blokland, D. E., 1965. En imposante hoos aun de Costa Brava (An impressive waterspout at Costa Brava), Hemel en Dampkring, LXV, 12, 348-349, The Hague.

CAstelló «CASTE», J., 2009. Costa Brava autèntica. Pagès editors.

GaYÀ, M. y Soliño, A. 1996. 'Caps de fibló' (trombas o tornados): algunas observaciones recientes. III Simposio Nacional de Predicción del INM, pp. 19-25. Instituto Nacional de Meteorología, Madrid. http:// hdl.handle.net/20.500.11765/3879.

GayÀ, M. y Redaño, A. 1999. El tornado de L'Espluga de Francolí. Medidas de campo y tratamiento de imágenes digitalizadas. IV Simposio Nacional de Predicción del INM, pp. 345-350. Instituto Nacional de Meteorología. Madrid. http://hdl.handle.net/20.500.11765/4278.

GAYÀ, M., 2015. Els Fiblons a Espanya: Climatologia i catàleg de tornados i trombes. Universitat de les Illes Balears.

Gayà, M., Llasat, M.-C. y Arús, J., 2011. Tornadoes and waterspouts in Catalonia (1950-2009), Nat. Hazards Earth Syst. Sci., 11, 1875-1883. doi: 10.5194/nhess-11-1875-2011, 2011. http://www.nat-hazardsearth-syst-sci.net/11/1875/2011/nhess-11-1875-2011.pdf.

JANSÀ, A., 1997. A general view about mediterranean meteorology: cyclones and hazardous weather. INM/WMO International Symposium on cyclones and hazardous weather in the Mediterranean, Mallorca, Spain, April 14-19.

López, J. M. y Arús, J., 2004. A Mediterranean derecho: Catalonia (Spain), 17th August 2003. Póster elaborado para la European Conference on Severe Storms (ECSS 2004) celebrada del 9-12 de noviembre de 2004 en León. http://hdl.handle.net/20.500.11765/5982.

LóPEZ, J. M., 2007. A Mediterranean derecho: Catalonia (Spain), 17th August 2003, Atmospheric Research, 83, 2-4, 272-283. https://doi.org/10.1016/j.atmosres.2005.08.008.

Mateo, J., Ballart, D., Brucet, C., Aran, M. y Bech, J., 2009. A study of a heavy rainfall event and a tornado outbreak during the passage of a squall line over Catalonia, Atmospheric Research, 93, 1-3, 131-146. https://doi.org/10.1016/j.atmosres.2008.09.030.

Morales, M.E., Arús, J., Llasat, M. C. y Castán, S., 2009. A database about the tornadic activity in Catalonia (NE Spain) since 1994. Plinius Conference Abstracts, 11, Plinius11-186, 11th Plinius Conference on Mediterranean Storms POSTER. http://hdl.handle.net/20.500.11765/5981.

Pascual, R. y Callado, A., 2002. Mesoanalysis of recurrent convergence zones in north-eastern Iberian Peninsula, Proceedings of Second European Conference on Radar in Meteorology and Hydrology (ERAD), Delft, Holland, 18-22 November 2002. 
Perea, C., 2018. La Helicidad Efectiva (SRHe) en la predicción de Supercélulas y Tornados. Curso Nuevos Desarrollos en el ATAPy en la DT de Cataluña. Barcelona.

PinEDA, N. et al., 2011. Aproximació a la climatologia de llamps a Catalunya: anàlisi de les dades de l'SMC per al període 2004-2008. Nota d'estudi del Servei Meteorològic de Catalunya, 73. http://static-m.meteo.cat/ wordpressweb/wp-content/uploads/2014/11/18130754/Nota_dEstudi_SMC_73_PRINT.pdf .

Plouvin, E., 2018. Tornade du 07 Janvier 2018, Pyrénées-Orientales, France. Enquête de terrain. https:// www.lasemaineduroussillon.com/wp-content/uploads/2018/02/Tornade-du-07-012018_Bilan_EricPlouvin_LecielduRoussillon_V3.pdf (último acceso, 26 de octubre de 2018).

Ramis, C., Arús, J., LóPez, J. M. y Mestres, A. M., 1997. Two cases of severe weather in Catalonia (Spain): an observational study. Meteorological Applications, 4, 207-217. doi: 10.1017/S1350482797000510.

RAmis, C., LóPez, J. M. y Arús, J., 1999. Two cases of severe weather in Catalonia (Spain). A diagnostic study. Meteorological Applications, 6 (1), 11-27. https://doi.org/10.1017/S1350482799000869.

RIESCO, J. et al., 2015. Climatología de tornados en España Peninsular y Baleares (http://www.aemet.es/ documentos/es/conocermas/publicaciones/Climatologia_tornados/Climatologia_tornados.pdf ).

Rodríguez, O., Bech, J., Soriano, J. D. y CAStán, S., 2018. A methodology for wind damage assessment from strong-convective winds events. A les XXIV Jornades Eduard Fontserè, Associació Catalana de Meteorologia, Barcelona. ISBN 978-84-946462-2-6. @ ACAM.

RodríGuEz, O. y BECH, J., 2018. Sounding-derived parameters associated with tornadic storms in Catalonia. Int. J. Climatol., 38, 2400-2414. doi:10.1002/joc.5343.

RodRíGuEZ, O., 2016. Estudi dels paràmetres derivats dels sondatges associats a tempestes tornàdiques. http://diposit.ub.edu/dspace/bitstream/2445/106044/1/TFM_OriolRodriguez.pdf.

Rodríguez, O., Bech, J., CASTÁn, S. y Arús, J., 2018. El tornado del 7 de gener de 2018: de l'Alt Empordà al Rosselló. Treball de camp i anàlisi de les destrosses. Poster, XXIV Jornades Fontsere. ISBN 978-84946462-2-6. @ACAM.

Sánchez-Laulhé, J. M., Rubin, J. B. y Arús, J., 2017. Las tromba marinas de San Feliu De Guíxols (2/IX/1965) y Málaga (8/III/1971): entre las más mediáticas del Siglo XX. Primera parte. Tiempo y Clima, 5, 56, Abril 2017. http://pkp.ame-web.org/index.php/TyC/article/view/1173.

Soliño, A., 2015. Estudio de los rastros de un tornado. Revista de Climatología, 15, 59-75. http:// www.climatol.eu/reclim/reclim17f.pdf.

Soliño, A. y GaYÀ, M., 1996. La Escala Fujita. Medida indirecta de la velocidad del viento en tornados: descripción y utilización en el reconocimiento de campo. III Simposio Nacional de Predicción del INM, pp. 13-18. Instituto Nacional de Meteorología, Madrid. http://hdl.handle.net/20.500.11765/3878.

Thompson, R. L., Mead, C. M. y Edwards, R., 2007. Effective Storm-Relative Helicity and Bulk Shear in Supercell Thunderstorm Environments. Wea. Forecasting, 22, 102-115. https://doi.org/10.1175/WAF969.1.

Wind Science And Engineering Center, 2006. A Recommendation for an Enhanced Fujita Scale (EF scale). http://www.spc.noaa.gov/faq/tornado/EFScale.pdf. 
